\title{
Feasibility analysis of a solar field for a closed unfired Joule-Brayton cycle
}

\author{
Francesco Rovense $^{1 *}$, Manuel S. Perez ${ }^{2}$, Mario Amelio ${ }^{1}$, Vittorio Ferraro ${ }^{1}$, Nino M. Scornaienchi ${ }^{1}$ \\ ${ }^{1}$ Department of Mechanical, Energy and Management Engineering, University of Calabria, Via P. \\ Bucci Edificio Cubo 46 C, 87063, Arcavacata di Rende (CS) Rende, Italy \\ ${ }^{2}$ Department of Energy Engineer, Escuela Técnica Superior de Ingeniería Universidad de Sevilla, \\ Camiino de los Descubrimientos, s/n. 41092 Sevilla, Spanish
}

Email: francesco.rovense@unical.it

\begin{abstract}
A solar tower for a closed unfired Joule-Brayton cycle is considered. An analysis for four different plants rated power levels is performed. The system here analyzed comprises an intercooled and regenerated gas turbine engine, a concentrating solar tower with pressurized volumetric receiver and a heat exchanger to perform cooling of the working fluid, allowing its recirculation. The plant scheme enables an output adjustment, using an auxiliary compressor. A constant value of the solar receiver outlet temperature approximately of $800{ }^{\circ} \mathrm{C}$, without use of fuel, in a large range of power, is obtained, guaranteeing a net thermal-to-electric efficiency around $40 \%$. Thermoflex@ has been used for the thermodynamics analysis and WinDelsol for solar field design and simulation (heliostat field and receiver). For the purposes of this work, it is assumed that the plant is located in Seville, Spain, with an annual direct normal irradiation (DNI) of 2,068 kWh $/ \mathrm{m} 2$.
\end{abstract}

Keywords: Concentrated Solar Power, Solar Gas Turbine, Heliostat Solar Field, Closed Joule-Brayton Cycle.

\section{INTRODUCTION}

The use of Gas-Turbines with concentrated solar tower has been under development for several decades, with early work performed in the 1980s by Scheuerer [1] and Schmuttermair [2] using a heavily modified ALLISON 250-C20B helicopter engine. Their research activities laid the groundwork for pressurized solar air receiver design, as well as dynamic simulation and control of solar gas-turbines. Since the beginning of the 2000s, a number of EU-funded projects have examined small-scale hybrid solar gas-turbines, such as the SOLGATE [3] and SOLHYCO [4] projects, which showed solarized micro gas-turbine units up to $250 \mathrm{kWe}$. These projects also allowed the demonstration of different types of high-temperature pressurized solar air receivers, with sustained outlet temperatures up to $960^{\circ} \mathrm{C}$. The SOLHYCO project also demonstrated the potential of using sustainably derived biodiesel as a hybridization fuel. Following the success of these small-scale units, a large-scale prototype was funded by the EU. SOLUGAS project allowed the construction of a solar hybrid gas turbine system of 4.6 MWe, based on a Mercury 50 [5]. Currently, the only gas-turbine solar hybrid system available on the market is produced by Aora-Solar [23] providing a unit $100 \mathrm{kWe}$ for off-grid and cogeneration applications. The Aora system has been successfully installed at test sites in Israel and Spain.

Some studies about the possibility of the use of only air as fluid work, was performed by a research financed from Google
[6] and recently our research group has examinated the use of storage [7] [24].

This latter option could be promising since complex technological combinations have just been taken into account from recent policy instruments, especially, for those ones related to solar energy deployment [20].

The system, shown in figure 1, is composed of three subsystems. First subsystem is made up by a solar tower, a heliostat field, in north field configuration and pressurized receiver. The second one is composed by an intercooled and regenerated gas turbine. In the third subsystem, we can find the cooling system, while the last subsystem is composed by an auxiliary compressor and a bleed valve. The facility layout is conceived to allow changing the air flow rate and, consequently, the power, by changing the density of the air flowing in the circuit (compressor, solar receiver, turbine and heat exchangers).

In figure 1 the red line shows the air flow path. By convention, it is considered that the cycle begins with the compression process, i.e. at the suction of the main compressor (3). At the end of the compression, the air is sent to the regenerator, where it passes through the cold side. After that, it enters into the solar receiver, where it is heated up to $800^{\circ}$ $\mathrm{C}$ by the concentrated solar flux, then is forwarded to the gas turbine. The solar radiation, on the receiver, it is absorbed inside the structure "volume" (volumetric effect). The air is forced through the absorber (a porous structure) and is heated by convective heat transfer [22]. In the pressurized volumetric 
receiver, the absorber is inside an internally insulated pressure vessel closed by a transparent quartz window and usually connected to a secondary concentrator. Because of the restricted size of quartz windows, a number of volumetric receivers (cluster) is required to achieve the desired power levels [4].

The air mass flow at turbine outlet (end of the expansion) is canalized toward the regenerator (hot side) and finally, to the low temperature heat exchanger to restart the cycle.

The power adjustments are obtained with the addition of air inside the closed system by the auxiliary compressor (8), so the internal air average density increases, or with the release of air to the atmosphere through the bleed valve (9) that results in reducing the internal air density. The mass flow rate circulating in the system (as well as the power) follows the density changes that, in turn, follow the available thermal solar power.

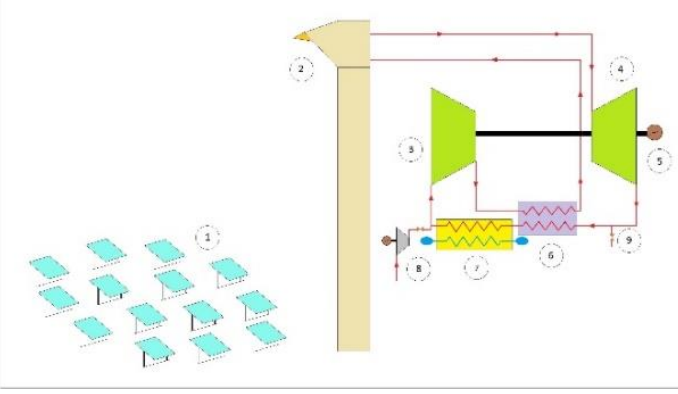

Figure 1. Closed loop solar Brayton cycle: 1. Heliostats field; 2. Solar tower;3. Compressor; 4. Turbine; 5. Electric generator; 6 . Regenerator; 7. Low temperature heat exchanger; 8. Auxiliary compressor; 9. Bleed valve

The basic idea of the proposed system is the adjustment of the air temperature at the solar receiver exit, which is kept constant without use of fuel. In the present work this temperature has been considered equal to the one at turbine inlet; no heat losses from the air passing from the receiver to the turbine have been taken into account.

As said before, the value of the base pressure of the cycle is modified by changing the amount of air contained within the system, then the average density and the mass flow rate, to obtain the temperature set point value at the output of the solar receiver.

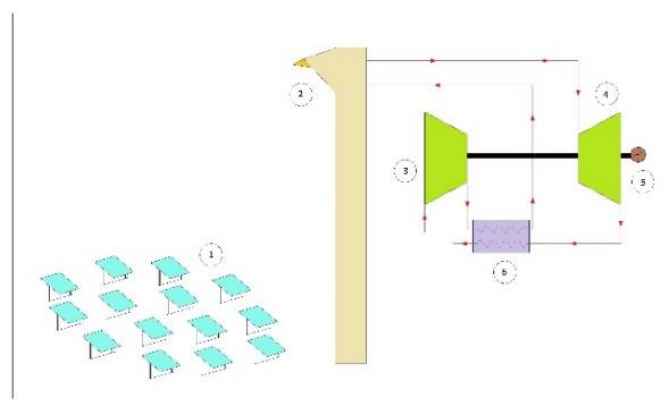

Figure 2. Open solar Brayton cycle: 1. Heliostats field; 2. Solar tower; 3. Compressor; 4. Turbine; 5. Electric generator; 6. Regenerator

We compared the results of these simulations, in terms of energy production and efficiency, with a reference plant with the same peak power but without density control. In this case, by IGV compressor and the throttle valve of the turbine, a different mass flow control was obtained.

Figure 2 shows the scheme of the open Brayton cycle used for the comparison; note that in this case the auxiliary compressor and low temperature heat exchanger are not present.

\section{METHODOLOGY}

The focus of this work is on the solar field performance; a preliminary analysis can be found in [8]. We examined the solar field for different engine rated power: $5 \mathrm{MW}, 10 \mathrm{MW}$, $20 \mathrm{MW}$ and $50 \mathrm{MW}$. These sizes have been used to compare the performances obtained from the simulations with others CSP plant currently in operational stage.

First, we will illustrate the simulation made on WinDelsol [17] and then the ones performed in Thermoflex [18].

The WinDelsol heliostat field models for each size have been used to simulate both plants with density control and with IGV control systems.

\subsection{Solar field system simulation}

In this study, we imposed some parameters, as the maximum exit air temperature from the receiver, the solar multiple and the heliostat size.

WinDelsol has been used to optimize the solar field, while, Thermoflex was employed to simulate the performance of the entire plant. We used results from the optimization and analysis with WinDelsol software, as the tower height, optical efficiency matrix, ratio between outer and inner radius, heliostats number, and receiver dimension.

An average flux incident on the receiver of $400 \mathrm{~kW} / \mathrm{m}^{2}$ [9] and an air temperature at the receiver outlet of $800{ }^{\circ} \mathrm{C}[10]$ are assumed. Previous work [19] has demonstrated the influence of the solar multiple (SM) with this kind of control system. In this work, a SM equal to 1.3, reasonable for a CSP system without storage, is assumed. Last parameters are the heliostat dimension and reflectivity, that were assumed of $120 \mathrm{~m}^{2}$ and $92 \%$, respectively [11].

To choose the DNI design point, we use the percentile 95 of the CDF from data of TMY3 of Seville [21], resulting in a design point $850 \mathrm{~W} / \mathrm{m}^{2}$. A switch off (threshold) DNI value of $300 \mathrm{~W} / \mathrm{m}^{2}$ was also assumed

Table 1 shows the data used in WinDelsol to design the solar fields for the four gas turbine rated power values.

Table 1. Data input in WinDelsol to design the heliostat field

\begin{tabular}{cc}
\hline Solar multiple & 1.3 \\
\hline Flux incident $\left[\mathrm{kW} / \mathrm{m}^{2}\right]$ & 400 \\
\hline Efficiency cycle & 0.4 \\
\hline Referring day & 172 \\
\hline DNI design $\left[\mathrm{W} / \mathrm{m}^{2}\right]$ & 850 \\
\hline Receiver absorbance & 0.97
\end{tabular}

To determine the radiative loss we using equation 1

$Q_{\text {rad }}=\alpha^{*} A^{*} \sigma^{*} T^{4}$

where: 
$\mathrm{T}$ is the maximum exit temperature of the receiver,

$\alpha$ is the absortance of the receiver surface at his mean temperature, $\mathrm{A}$ is the square receiver surface calculated by equation 2

$$
A=\frac{P_{T h, \max }}{\text { Flux }_{\text {incident }}}
$$

Incident flux is the average flux incident in and $\mathrm{P}_{\mathrm{Th} \text {,max }}$ is the maximum power incident into the receiver surface evaluated as:

$$
\begin{aligned}
& P_{T h, \text { max }}=P_{T h} * S M \\
& P_{T h}=\frac{P_{e l}}{\eta_{c}}
\end{aligned}
$$

$\mathrm{P}_{\mathrm{el}}$ is the electric power i.e. the power rate chosen for the analysis and $\eta_{c}$ is the cycle efficiency.

Table 2. Data receiver input in WinDelsol

\begin{tabular}{ccccc}
\hline $\begin{array}{c}\mathrm{P}_{\mathrm{el}} \\
{[\mathrm{MW}]}\end{array}$ & $\mathrm{P}_{\mathrm{Th}}[\mathrm{MW}]$ & $\mathrm{P}_{\text {Th, } \max }[\mathrm{MW}]$ & $\mathrm{A}\left[\mathrm{m}^{2}\right]$ & $\mathrm{Q}_{\mathrm{rad}}[\mathrm{kW}]$ \\
\hline 5 & 12,5 & 16,25 & 40,62 & 2963,4 \\
\hline 10 & 25 & 32,5 & 81,25 & 5926,8 \\
\hline 20 & 50 & 65 & 162,5 & 11853,6 \\
\hline 50 & 125 & 162,5 & 406,25 & 29634,0 \\
\hline
\end{tabular}

The convection losses were assumed from default of the code Delsol 3 [13].

In table 3 are resumed the main data related the solar field dimension using in the simulation to maximizing the optical efficiency.

Table 3 , shows the values of the sensibility analysis results performed on maximum ratio of outer and inner radius and span angle of the solar field.

The outer radius is the maximum radial distance in terms of equivalent tower heights that heliostats may be placed in the field.

The inner radius is the minimum radial distance in terms of equivalent tower heights that heliostats may be placed in the field. [13]

The span angle is the aperture of heliostat field in term of degree.

We used an optimization step of $2 \%$ so for the $5 \mathrm{MW}$ receiver orientation we used a value of $105^{\circ}$ [14]. A value of $90^{\circ}$ have been used for others solar fields.

Table 3. Data input in WinDelsol for each peak power

\begin{tabular}{ccccc}
\hline & 5 & 10 & 20 & 50 \\
& MW & MW & MW & MW \\
\hline $\begin{array}{c}\text { Minimum ratio outer/inner } \\
\text { radius }\end{array}$ & 0.9 & 0.9 & 0.9 & 0.9 \\
\hline $\begin{array}{c}\text { Maximum ratio outer/inner } \\
\text { radius }\end{array}$ & 10 & 10 & 10 & 12 \\
\hline Span angle $\left[{ }^{\circ}\right]$ & 100 & 100 & 90 & 120 \\
\hline
\end{tabular}

\subsection{Gas Turbine and heat exchanger simulation}

To simulate the entire plant, in particular the gas turbine system, as well as the heat exchangers, Thermoflex has been employed.

The output data calculated by WinDelsol software were used to characterize the solar field subsystem in Thermoflex, while the other subsystems were optimized in thermodynamic design by the software. We analyzed the performance in steady state condition in an interval of one hour, using the data taken from TMY3 of Seville.

To simulate both plants in Thermoflex software, we add hourly data of Azimuth and Zenith angle, as well as DNI, relative humidity and ambient temperature in the solar tower subsystem.

The main data used for the simulation of gas turbine at design point (open and closed loop) for each power plant, are resumed in table 4 .

Table 4. Gas turbine data

\begin{tabular}{cc}
\hline Pressure ratio & 6 \\
\hline Intercooler stage & 2 \\
\hline Compressor polytrophic efficiency [\%] & 87 \\
\hline Turbine polytrophic efficiency [\%] & 88 \\
\hline Estimated pressure loss in SF [\%] & 10 \\
\hline Mechanical efficiency [\%] & 98 \\
\hline
\end{tabular}

For the intercooler, regenerator and low temperature heat exchanger (present in the closed loop configuration) data in table 5 and 7 have been used.

Table 5. Regenerator of GT data

\begin{tabular}{cc}
\hline Thermal efficiency [\%] & 90 \\
\hline Normalized heat loss [\%] & 1 \\
\hline Minimum Pinch $\left[{ }^{\circ} \mathrm{C}\right]$ & 2 \\
\hline Hot side pressure drop [\%] & 3 \\
\hline Cold side pressure drop [\%] & 3 \\
\hline Design point UA $\left[\mathrm{kW} /{ }^{\circ} \mathrm{C}\right]$ & 257.7 \\
\hline
\end{tabular}

Table 6. Intercooler of GT data

\begin{tabular}{cc}
\hline Thermal efficiency [\%] & 90 \\
\hline Normalized heat loss [\%] & 1 \\
\hline Minimum Pinch $\left[{ }^{\circ} \mathrm{C}\right]$ & 2 \\
\hline Hot side pressure drop [\%] & 3 \\
\hline Water side pressure drop [\%] & 5 \\
\hline Design point UA $\left[\mathrm{kW} /{ }^{\circ} \mathrm{C}\right]$ & 266.4 \\
\hline $\begin{array}{c}\text { Temperature air outlet state after first } \\
\text { stage }\left[{ }^{\circ} \mathrm{C}\right]\end{array}$ & 35 \\
\hline
\end{tabular}

\subsubsection{Closed Brayton cycle}

For the characterization of the closed cycle, illustrated in figure 1, we have to impose the maximum inlet base pressure of 5 bar. The reason is the issue of the maximum pressure resistance of the receiver materials; the literature [15] considered as maximum value 30 bar. 
Table 7. Low temperature heat exchanger data

\begin{tabular}{cc}
\hline Thermal efficiency [\%] & 90 \\
\hline Normalized heat loss [\%] & 1 \\
\hline Minimum Pinch $\left[{ }^{\circ} \mathrm{C}\right]$ & 2 \\
\hline Hot side pressure drop $[\%]$ & 3 \\
\hline Water side pressure drop $[\%]$ & 5 \\
\hline Design point UA $\left[\mathrm{kW} /{ }^{\circ} \mathrm{C}\right]$ & 197.7 \\
\hline Temperature air outlet state $\left[{ }^{\circ} \mathrm{C}\right]$ & 35 \\
\hline
\end{tabular}

Table 8. Average losses for cosine, shadowing+ blocking, trasmissivity spillage and total for each size

\begin{tabular}{ccccc}
\hline & $5 \mathrm{MW}$ & 10 & 20 & 50 \\
& & MW & MW & MW \\
\hline Cosine & 0.848 & 0.85 & 0.856 & 0.844 \\
\hline Shadowing+ Blocking & 0.961 & 0.965 & 0.97 & 0.974 \\
\hline Trasmissivity & 0.96 & 0.95 & 0.942 & 0.914 \\
\hline Spillage & 0.917 & 0.932 & 0.954 & 0.963 \\
\hline Total & 0.661 & 0.669 & 0.687 & 0.667 \\
\hline
\end{tabular}

During the simulation, the code calculates automatically basic pressure of the cycle, mass flow of the entire plant, power produced, efficiency of the cycle, and other relevant parameters, when DNI, azimuth and zenith angle are varied.

A value of base temperature cycle of $35^{\circ} \mathrm{C}$ has been considered, not depending in this case of ambient air temperature

When the maximum flux incident on the receiver surface is reached, the code calculates the percentage of heliostat to be defocused to keep constant the radiant power incident on the receiver and the mass flow rate (at its maximum too).

\subsubsection{Open Brayton cycle}

Figure 2 shows the open Brayton cycle; in this case, the control of the receiver outlet air temperature, in open cycle, is performed by IGV of the compressor.

In this case we imposed the maximum temperature of the solar field, and the code calculated the mass flow value, closing or opening the valve.

In this case, we have performed the simulation considering the ambient air temperature, while the exit air from the turbine does not restart the cycle as in the closed loop.

\section{RESULTS}

In this part, we will show the analysis result; first, the ones related the solar field, obtained by WinDelsol, in terms of tower height, optical losses of the heliostat field, pipes thermal losses and parasitic losses.

Then, the annual simulations, concerning entire plant have been performed by Thermoflow.

Figure 3 (a) shows the heliostat field for the $5 \mathrm{MW}$ power plant, 3 (b) for $10 \mathrm{MW}, 3$ (c) for $20 \mathrm{MW}$ and 3 (d) displays the field of $50 \mathrm{MW}$.

Table 8 resumed the result of average losses of the heliostat field, while table 9 show the WinDelsol simulation results at the design point.

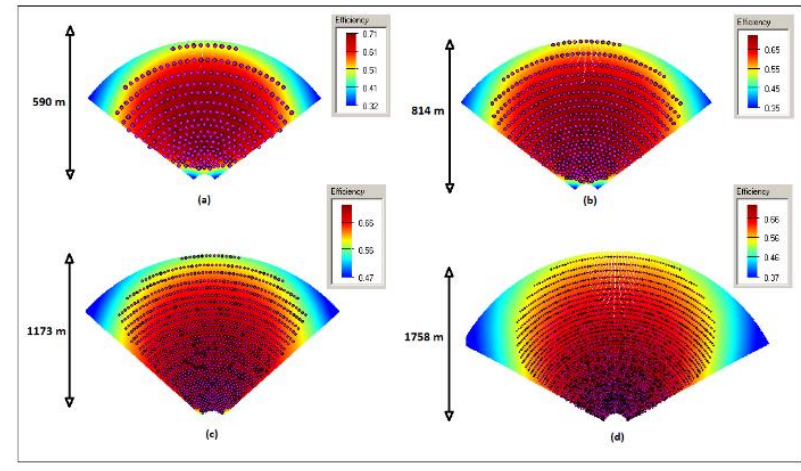

Figure 3. Heliostats fields. Figure 3 (a) $5 \mathrm{MW}$, figure 3 (b) $10 \mathrm{MW}$, figure 3 (c) $20 \mathrm{MW}$, figure 3 (d) $50 \mathrm{MW}$.

Table 9. Windelsol result simulation

\begin{tabular}{ccccc}
\hline & $\begin{array}{c}5 \\
\text { MW }\end{array}$ & $\begin{array}{c}10 \\
\text { MW }\end{array}$ & $20 \mathrm{MW}$ & $50 \mathrm{MW}$ \\
\hline Tower height [m] & 61,05 & 82,11 & 118,42 & 151,05 \\
\hline Field outer radius [m] & 590 & 814 & 1173 & 1758 \\
\hline Heliostat number & 305 & 583 & 1142 & 2930 \\
\hline $\begin{array}{c}\text { Power onto reflective } \\
\text { surface [MW] }\end{array}$ & 34,57 & 66,68 & 132,24 & 341,22 \\
\hline $\begin{array}{c}\text { Design point optical } \\
\text { heliostat field efficiency }\end{array}$ & 0,68 & 0,68 & 0,69 & 0,66 \\
\hline $\begin{array}{c}\text { Gross Power onto receiver } \\
\text { [MW] }\end{array}$ & 23,57 & 45,84 & 91,45 & 227,51 \\
\hline Receiver efficiency & 0,79 & 0,82 & 0,82 & 0,82 \\
\hline $\begin{array}{c}\text { Power to working fluid } \\
\text { [MW] }\end{array}$ & 18,24 & 36,65 & 73,04 & 182,74 \\
\hline Power to turbine [MW] & 14,03 & 28,19 & 56,18 & 140,51 \\
\hline $\begin{array}{c}\text { Piping thermal losses } \\
\text { [MW] }\end{array}$ & 0,52 & 0,99 & 2,02 & 4,08 \\
\hline
\end{tabular}

Figures 4 shows the flux maps in 3 dimensions for each size of the receiver; as possible to note in figure 4 (a), the best efficiency for the $5 \mathrm{MW}$ power plant can be obtained orienting around $15^{\circ}$ the tilt receiver angle.

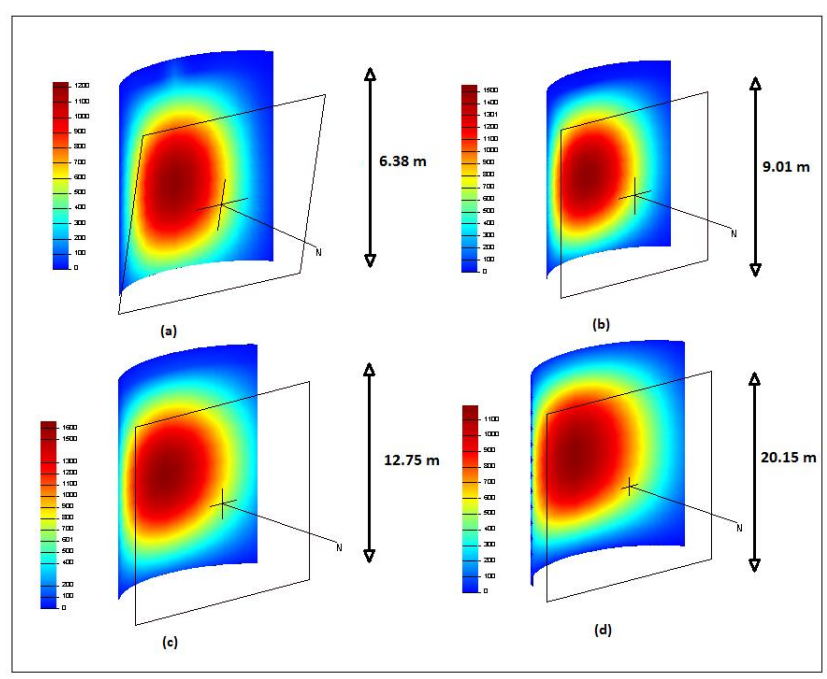

Figure 4. Flux maps 3D of receivers. Figure 4 (a) $5 \mathrm{MW}$, figure 4 (b) $10 \mathrm{MW}$, figure 4 (c) $20 \mathrm{MW}$, figure 4 (d) 50 MW. 


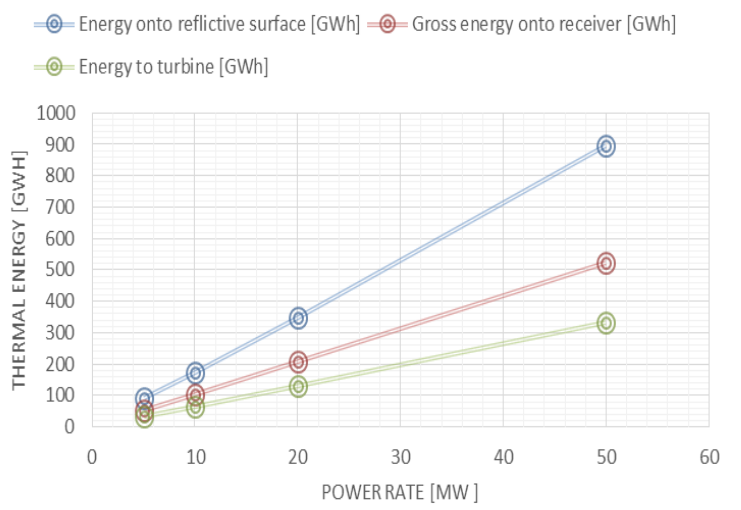

Figure 5. Annual heliostats field performance.

Figure 5 shows the annual heliostat field performance, obtained by WinDelsol, the energy available on the solar field (blue line), the one on the receiver (red line), and finally (the one green) the useful thermal power delivered to the GT.

Results of the Thermoflex simulation show how the plant with density control system in closed loop cycle can achieve, in all size analyzed, an average annual efficiency about $40 \%$.

In table 5 are summarized the energy production and the average efficiency of closed loop cycle.

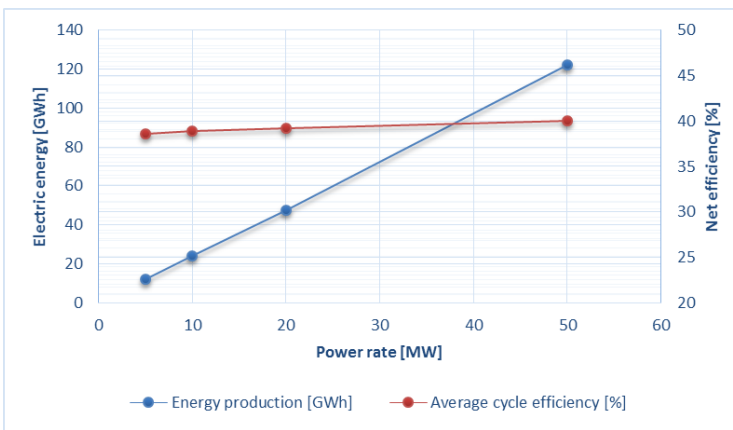

Figure 6. Annual electric energy production [GWh] and yearly average net electric efficiency [\%] vs Power rate for closed cycle.

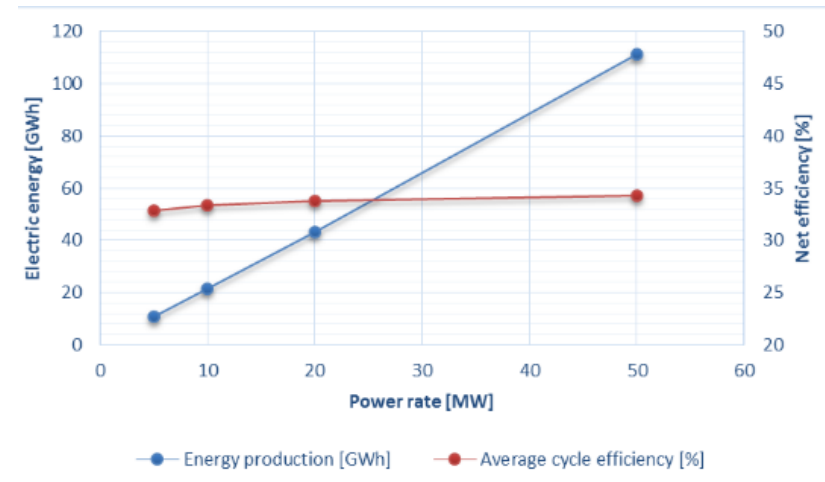

Figure 7. Annual electric energy production [GWh] and yearly average net electric efficiency [\%] vs Power rate for open cycle.

As can be seen in Figure 6, the energy production (blue line) increases consistently with the feeding rate, while the annual average electrical efficiency remains almost constant at the level of about $40 \%$.
The best configuration, in terms of efficiency, is the plant of $50 \mathrm{MW}$, with a value of $40.04 \%$ and an energy production of 121.91 GWh.

All plants, as showed by the analysis can work for about 2000 hours per year, without use of fuel.

In figure 7, the results of the plant with IGV control system of GT (open cycle) are shown.

We can observe that the energy production, using this kind of control system is lower than the one with density control; the average annual efficiency is less too and it is not constant in all size configurations. The difference, in term of percentage of energy production, between both control systems analysed for all cases, is about $9 \%$. The main difference is for $50 \mathrm{MW}$ configuration that is about $10 \mathrm{GWh}$.

\section{DISCUSSION}

The analysis in the work shows how the energy production of the analyzed plants is comparable with that of solar central receiver system currently in operational stage.

For example, we can consider the PS 10 [16] and PS 20 that have an energy production of about $20 \mathrm{GWh}$ and $48 \mathrm{GWh}$ respectively using a small storage. In the plants analyzed in this work of same size, results show that energy production is of $24 \mathrm{GWh}$ for the $10 \mathrm{MW}$ plant and of about $47 \mathrm{GWh}$ for the 20 MW plant.

\section{CONCLUSIONS}

A feasibility analysis of a solar field feeding a closed unfired Joule-Brayton cycle has been carried out. The plant can adjust power output by the air density control. Using WinDelsol, the solar field was analyzed for several sizes, and then the behavior of each whole plant was simulated by Thermoflex.

The configuration with best efficiency among those considered is the $50 \mathrm{MW}$ rated power plant, to which correspond an energy production of $121.91 \mathrm{GWh}$ and an average annual efficiency of $40 \%$; this plant can produce 10 GWh more energy than a solar tower system with an unfired ordinary GT, whose power adjustment is performed by IGV. A similar power block does not seem viable today in CSP plants, since solar-only plants would directly compete with much cheaper PV technology.

\section{FURTHER WORK}

Gas turbine power block in CSP plants is instead attractive in hybrid Configuration, to keep constant the performances at peak level. The hybrid plant retains greater simplicity but it is penalized by the consumption of natural gas and by the reduction of operating hours for switching off on days when high variability of DNI and, as a consequence, high fuel consumption, are expected. Generally the closed loop cycle, where the control of the density has been proposed, has a constant efficiency about of $40 \%$ in all size configurations and allows to control the maximum temperature of the cycle in a large range of thermal power; moreover, the use of storage as well as the use of other working fluid might increase the operational hours. 


\section{REFERENCES}

[1] Scheuerer K. (1986). Berechnung des stationären und In-stationären betriebsverhaltens von solarkraftanlagen mit paraboloidkonzentrator und gasturbine, $\mathrm{PhD}$ Thesis, Technische Universität, München.

[2] Schmuttermair H. (1992). Experimentelle simulation und analyse des betriebsverhaltens einer solarkraftanlage mit gasturbine, $\mathrm{PhD}$ Thesis, Technische Universität, München.

[3] European Commission. (2005). Solgate: Solar hybrid gas turbine electric power system, Final Publishable Report, Directorate-General for Research, Brussels.

[4] Heller P., Pfänder M., Denk T., et al. (2006). Test and evaluation of a solar powered gas turbine system, Solar Energy, Vol. 80, pp. 1225-1230.

[5] Queroa M., Korzynietzb R., Ebertc M., Jiméneza A.A. (2014). A. del Ríoa, JA. Briosoa- solugas - operation experience of the first solar hybrid gas turbine system at MW scale, solar paces 2013, Energy Procedia, Vol. 49, pp. $1820-1830$

[6] Thomas P.K. (2009) Solar energy conversion using Brayton cycle system, US Patent 20090308072 A1.

[7] Rovense F., Amelio M., Ferraro V., Scornaienchi N.M. (2016). Analysis of a concentrating solar power tower operating with a closed joule Brayton cycle and thermal storage, International Journal of Heat and Technology, Vol. 34, No. 3, pp. 485-490. DOI 10.18280/ijht.340319

[8] Rovense F. (2015). A case of study of a concentrating solar power plant with unfired Joule-Brayton cycle, 70th Conference of the Italian Thermal Machines Engineering Association, ATI 2015 Energy Procedia, Vol. 82, pp. 978-985. DOI: 10.1016/j.egypro.2015.11.855

[9] Ávila-Marín A.L. (2001). Volumetric receivers in solar thermal power plants with central receiver system technology, Solar Energy, Vol. 85, No. 5, pp. 891-910. DOI: 10.1016/j.solener.2011.02.002

[10] William B.S., Geyer M. (2001). Power cycles for electricity generation, power from the sun.optimum operating temperature, Polytechnic University, Pomona, California.

[11] Zhou Y., Zhau Y. (2014). Heliostat field layout design for solar tower power plant based on GPU, 19th IFAC World Congress Proceedings.

[12] Wilcox S., Marion W. (2008). User's manual for tmy3 data sets, National Renewable Energy Laboratory, Colorado, USA, Technical Report, NREL/TP-58143156.

[13] Kistler B.L. (1986). A user's manual for DELSOL3: A computer code for calculating the optical performance and optimal system design for solar thermal central receiver plants, Sandia Report.

[14] Guo S., Liu D.Y., Wang F., Zhang Y.M. (2009). Power and energy engineering conference, APPEEC 2009, Asia-Pacific. DOI: 10.1109/APPEEC.2009.4918625

[15] Karni J., Kribus A., Rubin R., Doron P., Fiterman A., Sagie D. (1997). The DIAPR: A high-pressure, high temperature solar receiver, Journal of Solar Energy Engineering. DOI: 10.1115/1.2871853

[16] Solúcar. (2002). $10 \mathrm{MW}$ solar thermal power plant for southern spain- project- PS10, Inabensa Fichtner, Ciemat, DLR, Spain, Sanlucar la Mayor, Technical Report NNE5-1999-356.

[17] WinDelsol 3.0, "Users Guide". (2002). Aicia, cimeat solucar, Spain, Sanlucar la Mayor.

[18] THERMOFLEX Fully-Flexible Heat Balance Engineering Software. (2016). Thermo flow Inc. 2 Willow Street, Suite 100, Southborough, MA 017451020, USA.

[19] Amelio M., Beraldi P., Ferraro V., Scornaienchi M., Rovense F. (2016). Optimization of heliostat field in a thermal solar power plant with an unfired closed JouleBrayton Cycle, 71st Conference of the Italian Thermal Machines Engineering Association, ATI 2016; Politecnico di Torino, Vol. 101, pp. 472-479.

[20] Benedetto N., Di Matteo U. (2016). Solar energy technologies in sustainable energy action plans of italian big cities, Energy Procedia, Vol. 101, pp. 10641071, 1876-6102. DOI: 10.1016/j.egypro.2016.11.136

[21] Moreno T.S., et al. (2016). Solar resource assessment in Seville, Spain, statistical characterisation of solar radiation at different time resolutions, Solar Energy, Vol. 132, pp. 430-441.

[22] Blanco M.J., Santigosa L.R. (2017). Next generation of liquid metal and other high-performance receiver designs for concentrating solar thermal (CST) central tower systems, Advanced in Concentrating Solar Thermal Research and Technology, $1^{\text {st }}$ Edition, Amsterdam, Boston, Heidelberg, London, New York, Oxford, Paris, San Diego, San Francisco, Singapore, Sydney, Tokyo, Elsevier, Vol. 7, pp.132-133.

[23] Tulip A. (2012). Joining hands through sustainable energy for sustainable livelihoods, Overview of the Technology Solution, from www.aora-solar.com

[24] De L., Ferraro F., Marinelli V.V. (2015). On the performance of CSP oil-cooled plants, with and without heat storage in tanks of molten salts, Energy, Vol. 82, pp. 230-239.

\section{NOMENCLATURE}

$\begin{array}{ll}\mathrm{Q}_{\mathrm{rad}} & \text { Receiver radiative loss }[\mathrm{kW}] \\ \alpha & \text { Receiver absortance } \\ \mathrm{A} & \text { Receiver surface }\left[\mathrm{m}^{2}\right] \\ \sigma & \text { Stefan Boltzmann constant }\left[\mathrm{W} / \mathrm{m}^{2} \mathrm{~K}^{4}\right] \\ \mathrm{P}_{\text {Th,max }} & \text { Maximum thermal power incident into the } \\ & \text { receiver }[\mathrm{MW}] \\ \mathrm{Flux}_{\text {incident }} & \text { Incident flux in receiver }\left[\mathrm{MW} / \mathrm{m}^{2}\right] \\ \mathrm{P}_{\mathrm{Th}} & \text { Thermal power }[\mathrm{MW}] \\ \mathrm{SM} & \text { Solar multiple } \\ \mathrm{P}_{\mathrm{el}} & \text { Electric power rate }[\mathrm{MW}] \\ \eta_{\mathrm{c}} & \text { Cycle efficiency } \\ \mathrm{GT} & \text { Gas Turbine } \\ \mathrm{IGV} & \text { Inlet guide vanes }\end{array}$

